\title{
Long-term professional performance of minimally invasive surgery post-graduates
}

\section{Desempenho profissional, em longo prazo, dos egressos do programa de pós graduaçåo em cirurgia minimamente invasiva}

Marcelo de Paula loureiro, tCBC-PR'; Christiano Maggi Claus'; Eduardo Aimoré Bonin'; Antonio Cury Filho'; Danielson

Dimbarre ${ }^{1}$; Pedro TrauczinskI ${ }^{2}$; Lee SWanstrom ${ }^{3}$

A B S T R A C T

\begin{abstract}
Objective: to evaluate the contribution of a post-graduation program in surgeons professional careers. Methods: participants were asked to answer a questionnaire with questions related to possible changes in their professional performance after the end of the course. Results: forty-three $(76.7 \%)$ of the 56 participants eligible for the study responded to the questionnaires. Most participants, 32 (74.4\%), had previous contact with laparoscopic surgery; however, only 14 (32.5\%) reported the experience as primary surgeon. The expectations on the course were reached or exceeded for $36(83.7 \%)$ participants. Thirty-seven (86\%) incorporated minimally invasive procedures in their daily surgical practice, 37 (86\%) reported improvements in their income above $10 \%$ and $12 \%$ reported income increase of over $100 \%$, directly related to their increase of laparoscopic activity. Conclusion: the program in minimally invasive surgery provides a high level of satisfaction to its participants, enables them to perform more complex technical procedures, such as sutures, and improves their professional economic performance.
\end{abstract}

Key words: Laparoscopy. Education. Motor Skills. Teaching.

\section{INTRODUCTION}

The structured model of surgical education based in medical residency was proposed by Halsted over 100 years ago' ${ }^{1}$. In this, the operating room was the central environment of surgical skills acquisition over five to seven years of training. Although still present, it no longer responds to all surgeons' learning needs. The surgical education has undergone profound changes over the past two decades. Minimally invasive surgery (MIS) has created a growing demand for quality and high applicability medical information. Surgeons increasingly need to quickly learn new techniques and be able to use them with good results. In Brazil, about 200 residency programs in the area of surgery and their more than 1,000 offered vacancies are not able to offer, for the most part, sufficient MIS education for residents, as well as in other developing countries ${ }^{1-5}$

In addition to the deficiency in the formation of new residents, there is also the demand for surgical technical training for surgeons that ended their residency programs long ago and need to learn these new forms of treatment for the same disease for which they only learned "open surgeries". To meet this demand, many courses focused on learning of specific skills have been created and, at the same pace, disappeared. The commitment to surgical education requires dedication from the teacher surgeon and student involvement. In the case of MIS, there is also the creation and maintenance of expensive and complex pedagogical structures.

In 2004, the Jacques Perrisat Institute was founded in Curitiba, with the main objective to offer a thorough training opportunity in laparoscopic surgery for surgeons beginning their activity or for those who practice it.

The objective of this study was to evaluate the contribution of a post-graduation program in the professional careers of its graduates, one year after completing the course.

\section{METHODS}

The MIS post-graduation course was developed by the Jacques Perissat Institute (IJP), an independent center for surgical education in the city of Curitiba, in southern Brazil, in conjunction with the Positivo University

1. Post-Graduation Program in Minimally Invasive Surgery, Jacques Perissat Institute (IJP), Universidade Positivo, Curitiba, Paraná State - PR, Brazil; 2. St. Elizabeth Hospital, Blumenau, Santa Catarina State - SC, Brazil; 3. Legacy Institute of Surgical Innovation and Research, Portland, Oregon, USA. 
(www.up.com.br), a private institution that offers medical school also located in Curitiba.

\section{Description of the post-graduation program}

The Post-Graduation Program in Surgery Minimally Invasive (MIS) consists of eight modules designed to meet the needs from basic to advanced laparoscopy, and is intended for general surgeons or other surgical specialties. Each of the eight modules consists of three full days of immersion in laparoscopic surgery.

The modules cover the following topics: 1) Laparoscopy Principles and new technologies; 2) Upper Digestive Tract; 3) Hepatobiliary Surgery; 4) Abdominal Wall Defects and Access to the Retroperitoneal Space; 5) Minimally Invasive Thoracic Surgery; 6) Colorectal Surgery and Emergency in Laparoscopy; 7) Urologic and Gynecologic Laparoscopy; and 8) Metabolic and Bariatric Surgery.

The courses are coordinated and taught by five teachers of the permanent core of the Jacques Perissat Institute (IJP) and by invited experts from other parts of Brazil and other countries.

On the first day participants have eight hours of lectures, divided into two blocks. Morning sessions will cover laparoscopic anatomy, physiology and other basic concepts. The afternoon sessions include strategies and step by step description of surgical techniques, indications, complications and results related to the module topic. At the end of the lectures, the participants perform a test with multiple choice questions.

The second day consists of live broadcast operations related to the module's theme and discussed in an interactive learning environment. There are two operating rooms equipped for high definition transmission of surgical procedures in the hospital auditorium that seats up to 100 participants. The faculty conducts an average of eight operations per day, and during the breaks between the live procedures, edited videos are presented by the moderators describing the details of each technique.

The third day includes practice in living tissue in the animal facility of the University (Figure 1). The practice in animals, pigs, is tutored by one teaching assistant per table of up to three students, and is focused on the development of cognitive and manual skills to enable participants to simulate in the animals the procedures watched live the day before.

Moreover, anastomosis and suture techniques, dissection, holding and traction are taught and practiced in the exercise room in simulation models in synthetic fabrics, the so-called "dry lab". This is divided into six stations where activities are timed and supervised by faculty members (Figure 2).

Being a broad sense post-graduation program, it follows the rules established by the Ministry of Education. Participants must fulfill 420 hours of training; they are also are required to follow the IJP Surgery Service for one week, when directly participating in the operations, and there is an end of course work, in accordance with the technical and scientific standards of the University. Only then participants are entitled to receive a certificate of specialization in Laparoscopic Surgery.

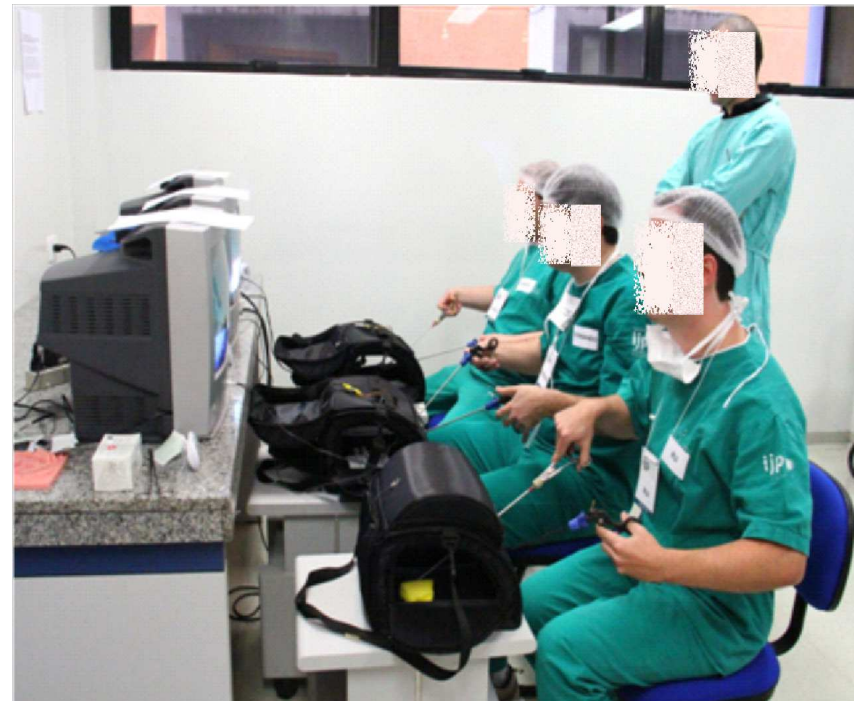

Figure 2 - Detail of students in practice with the laboratory simulators ("dry lab").

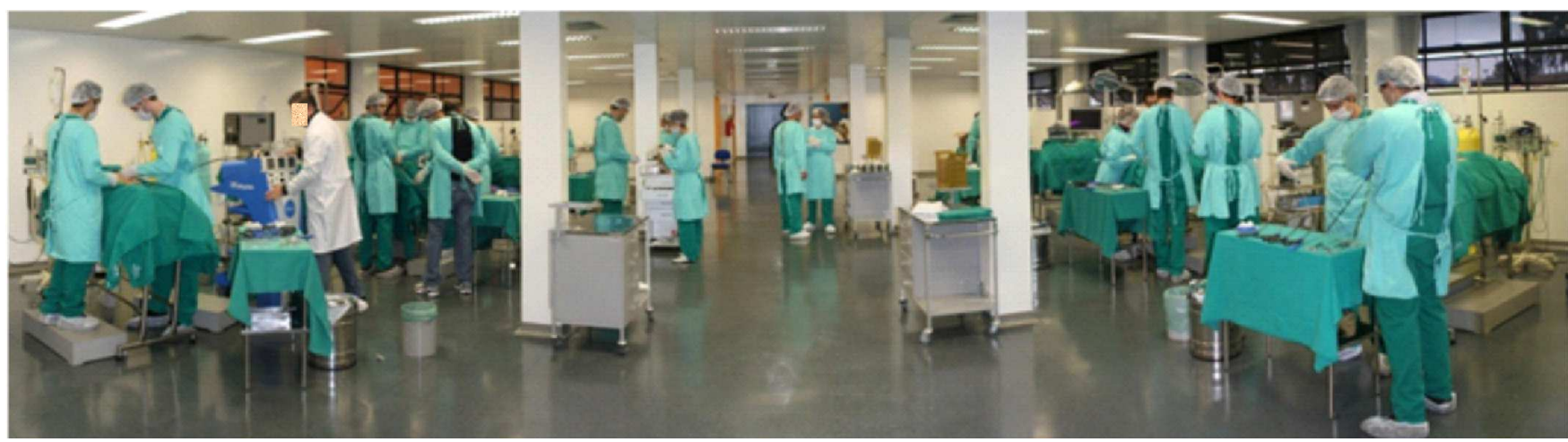

Figura 1 - Perspective of the Universidade Positivo vivarium for training in animals 


\section{Study design}

All participants in the MIS Post-Graduation Program of the Jacques Perissat Institute between 2005 and 2009 were invited to participate.

We collected basic demographic data at the time of enrollment in the course. Age, gender, level of surgical training, current practice profile, and previous experience in MIS were evaluated. After completing the program, all participants received a structured questionnaire.

To better assess the impact of such training in clinical practice, only those who had completed the course at least one year before were considered to participate. Questionnaires were sent by letter or email and focused on the assessment of the expertise acquired after the course, comparing with pre-course expectations. In addition, we assessed the professional and economic impact of the course in their lives. All data are presented as descriptive statistics.

\section{RESULTS}

\section{and previous experience. \\ Profile of MIS Post-Graduation participants}

Forty-three $(76.7 \%)$ of the 56 participants in the program eligible for the study responded to questionnaires and had their answers matched and compared with the ones provided at the beginning of the course. There were 38 men and five women. They had completed the postgraduation program in an average of 2.18 years ( $1-5$ years). Twenty-four ( $56 \%$ ) were between 25 and 40 years of age. Nineteen $(44 \%)$ started the program less than five years after completion of residency training, while 10 (23.2\%) had completed residency more than 20 years before. Fourteen participants $(32.5 \%)$ were from cities with less than 200,000 inhabitants, while the majority (67.5\%) was from larger cities.

Thirty-two participants (74.4\%) had previous contact with laparoscopic surgery and $14(32.5 \%)$ reported experience in the performed procedures as the primary surgeon. Prior to the course, seven of these participants operated only less complex laparoscopic procedures, such as cholecystectomies, while the other seven performed intermediate or advanced complex procedures, such as fundoplication or colectomy (Figures 3 and 4).

\section{the Post-Graduation}

\section{Motivations and expectations regarding}

The main motivation of students to start the course were learning and the development of new techniques for 16 of them (37.2\%) and the interest in the long-term course format. Eight students (18.6\%) participated in the program to keep their knowledge up to date.

Thirty-two (74.4\%) were defined as "active participants" throughout the program. Three (7\%) confessed

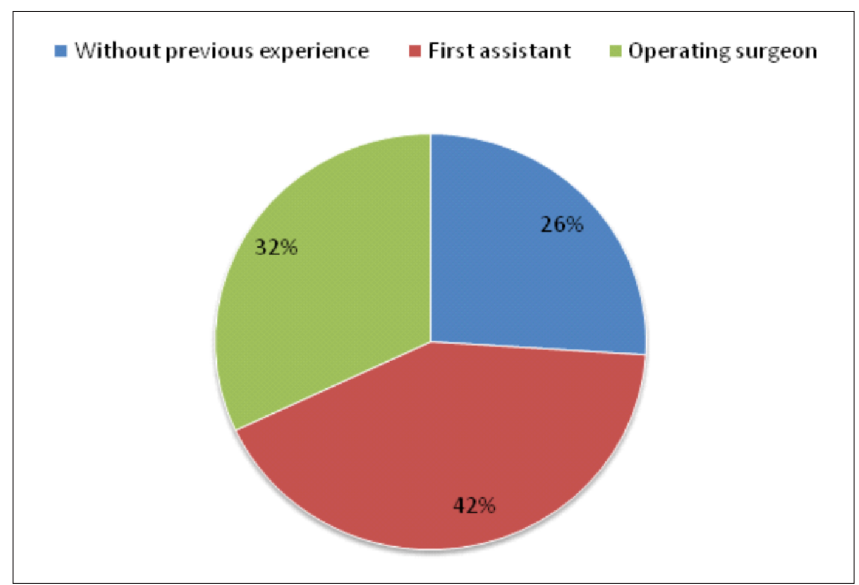

Figure 3 - Previous experience in laparoscopy before starting the MIS course.

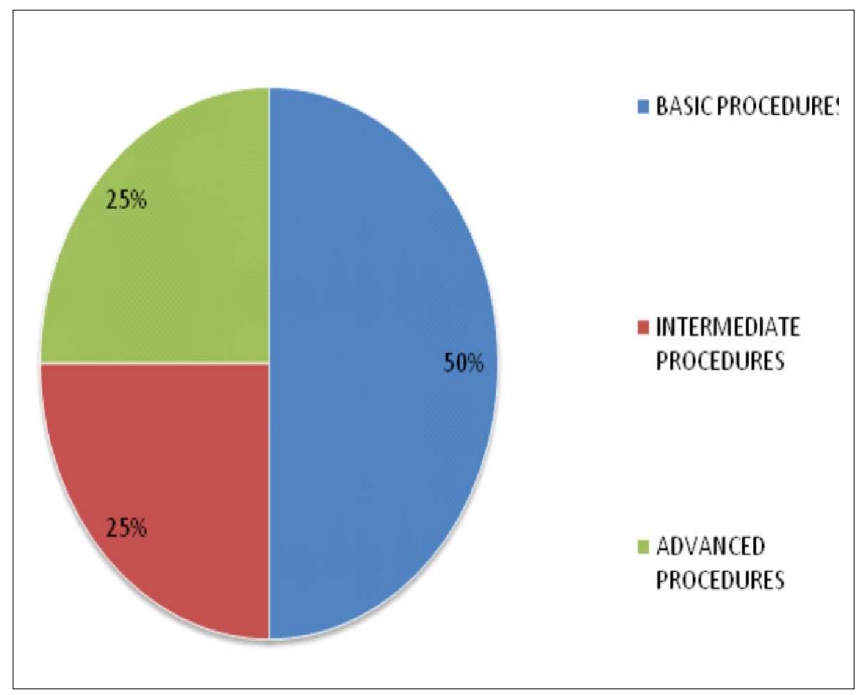

Figure 4 - Laparoscopic procedures performed before starting the MIS course.

little involvement. The expectations regarding the purpose of the course were fully achieved for $36(83.7 \%)$ them. Seven $(16.2 \%)$ had partially met expectations. Of these, five $(71.4 \%)$ were older than 40 years.

\section{Professional and Economic Impact}

Thirty-seven participants (86\%) incorporated minimally invasive procedures in their daily surgical practice. Only six (13.9\%) of the evaluated students mentioned not incorporating minimally invasive procedures to their routines. The main barrier to the adoption of MIS, both basic and advanced, was the lack of investment in infrastructure / equipment by hospital where they worked.

Considering the participant's self-perception of their technical skills, $28(65.1 \%)$ felt fully able to perform laparoscopic suturing; 10 (23.2\%) felt suitable, but slow; and five (11.6\%) still felt unsafe to perform laparoscopic suturing. Three of these five (60\%) were over 40 years of 
age. Prior to the course, seven (16.2\%) felt able to perform laparoscopic suturing.

Twenty-six (60.4\%) participants reported that the course improved their basic knowledge and increased their professional self-confidence. Thirty-four (79.06\%) began to use or increased their use of endoscopic stapler. Seventeen (39.53\%) now hold more than 100 minimally invasive procedures per year (Figure 5). One student reported that completion of the course did not provide any impact on his professional practice (Figure 6).

As for the professional economic impact, six (13.9\%) reported that the completion of the program did not affect their performance. Thirty-seven $(86.04 \%)$ reported improvement in their yields higher than $10 \%$, and $12 \%$ of these reported increase of over $100 \%$ with the introduction of laparoscopic.

\section{DISCUSSION}

The training in minimally invasive surgery (MIS) during surgical residencies in general is insufficient for the newly formed surgeons safely start their laparoscopic practice $^{2-6}$. Several reasons justify this reality. On the one hand, there is lack of access to minimally invasive technology in public hospitals, where a substantial proportion of patients in Brazil receive their health care services and where much of the surgical residency training takes place. On the other, there is high cost of laparoscopic devices and their maintenance, which causes cumulative deterioration of the supplies, which when purchased, typically are already outdated. Furthermore, there is still the lack of understanding that, for the resident to acquire expertise in minimally invasive surgery, residency programs should undergo a profound restructuring, without which clinical outcomes may be worse than expected in conventional surgery. Finally, the surgical training is still dominated by conservative attitudes toward advances in surgical technologies, which then delay the practical adoption of new concepts.

Thus, several generations of Brazilian surgeons currently in practice are still unable to incorporate laparoscopy into their routines. In addition, there is increasing requirement for the use of new minimally invasive techniques by a demanding and every day better informed public. In an era of internet for all and evidence-based medicine, MIS has become a right of the patient and almost a duty for the surgeon.

There are many MIS courses of different modalities. Most of them, however, will disappear as rapidly as they are created. The lack of structure, clear educational objectives and follow-up of former students to better evaluate their results are some of the causes for the failure of such courses. Although they serve the immersion objective, the swift exposure, often without appropriate methodology, does not allow to apply the didactic principles

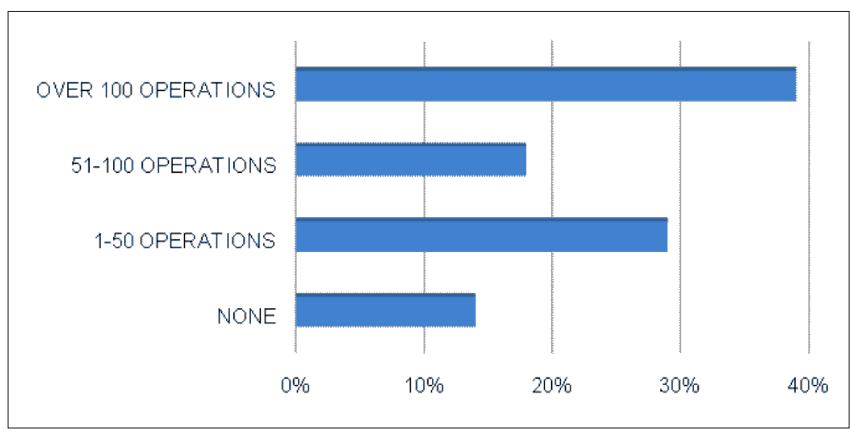

Figure 5 - Laparoscopic procedures performed one year after finishing the Minimally invasive surgery (MIS) course.

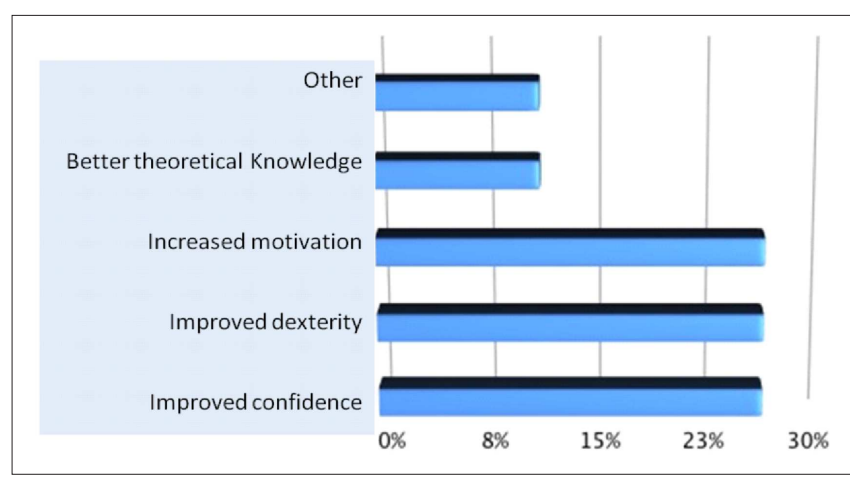

Figure 6 - Behavioral change after completion of the MIS course.

of repetition and gradual accumulation of knowledge. For this reason, they are usually not sufficient to promote the full domain of techniques and skills in MIS ${ }^{12}$.

One third of our students feel frustrated with the results of previously completed short courses. Indeed. this has been the motivation to seek a longer course with postgraduate structure.

The impact of training courses in MIS can be remarkable. Gröne et al. reported that the capability of performing laparoscopic sutures after a week of a basic course increased from 56 to $93 \%$ and the ability of making an anastomosis, from 21 to $60 \%$. They also noted that $89 \%$ of participants reported that these courses should be integrated as part of the residency training ${ }^{13}$.

The IJP has developed an education program in MIS using a model designed to solve some of the problems common to short courses. Formatted into a 12-month program, it consists of eight different modules designed to expose participants to different techniques. The modules are short enough and sequential to facilitate the implementation and use of minimally invasive techniques for both already formed and still resident surgeons. In fact, $44 \%$ of our students started the program directly after finishing residency. Moreover, $23.2 \%$ had completed residency more than 20 years before. These figures show that there is a huge demand for continuing education in surgical new procedures and technologies. 
The practical focus of the course is the repetitive skills training, allowing its gradual acquisition. Thus, given the individual development of each student, one can increase the degree of difficulty of the taught procedures. The principles of these teaching methods are based on wellestablished doctrines: 1. Identify the skill to be learned; 2Provide the theoretical basis of the skill understanding and contextualize it for everyday use; 3 - Develop exercises to practice it; 4- demonstrate the standard of such practice; 5- Supervise its training; and 6- objectively evaluate its execution ${ }^{14}$.

The 43 participants who completed the course over a year later later returned to their work environment. The questionnaires showed that $83.7 \%$ of them had their prior expectations fully met by the course. Equally remarkable is that $86 \%$ of students reported an increase in their income with the addition of new minimally invasive surgery practices.

In addition to the practical focus on MIS courses, one should also look to counteract some other disabilities. The skills of a good surgeon go far beyond simple technical capacity ${ }^{15-17}$. As important as the techniques are the basic knowledge of medical, clinical judgment and the objective decision-making. Other elements, such as professionalism and clear communication skills are also critical components of the formation of a surgeon and are learned only with time and guidance.

Particularly encouraging to the program was the objective identification of its changing impact in participants' daily practice. Eighty-six percent of them began to perform laparoscopic procedures in their routines. The importance of such a change in the surgeon's community is huge. Without a local competent professional, patients seeking a less invasive alternative to conventional surgery are required to look for them in other cities. Thirty-eight (88.3\%) participants reported that they were able to perform endoscopic suturing with comfort and safety, a significant result that suggests training for advanced laparoscopic procedures by the end of the program.

The overall results show the improvement of the quality of operations, and also for the professional and economic development of the surgeon. The commitment to surgical education requires deep engagement of educators, as well as deep involvement of participants.

In conclusion, the Minimally Invasive Surgery Course of the Jacques Perissat Institute provided a high level of satisfaction to its participants, enabled them to perform more complex technical procedures, such as sutures, and improved their professional economic performance.

\section{Acknowledgements}

We thank the Santa Cruz Hospital, seat for five years of our live operations; the Ecoville Hospital, where this activity currently takes place; and Professor Jacques Perissat, eternal source of inspiration to the Institute that bears his name.

\section{R E S U M O}

Objetivo: avaliar a contribuição de um programa de pós-graduação na carreira profissional de seus egressos. Métodos: os participantes foram convidados a responder questionário com perguntas relacionadas a eventuais mudanças em seu desempenho profissional após o término do curso. Resultados: quarenta e três $(76,7 \%)$ dos 56 participantes elegíveis para o estudo responderam aos questionários. A maioria dos participantes, 32 (74,4\%) já tinha contato prévio com a cirurgia laparoscópica, porém, apenas $14(32,5 \%)$ relataram a experiência como cirurgião principal. As expectativas sobre o curso foram alcançadas ou superadas para 36 $(83,7 \%)$ participantes. Trinta e sete $(86 \%)$ incorporaram procedimentos minimamente invasivos em sua prática cirúrgica diária. E também 37 (86\%) relataram melhorias em seus rendimentos superiores a 10\%, e ainda 12\% relataram aumento superior a $100 \%$ em seus rendimentos, diretamente relacionado com o incremento da atividade laparoscópica. Conclusão: o programa em cirurgia minimamente invasiva proporciona um elevado grau de satisfação aos seus participantes, e os capacita a realizar procedimentos técnicos mais complexos, como as suturas, além de melhorar seu desempenho economico profissional.

Descritores: Laparoscopia. Programas de Treinamento. Habilidade Motora. Ensino.

\section{REFERENCES}

1. Mayberry JC. Residency reform Halsted-style. J Am Coll Surg. 2003;197(3):433-5

2. Ferreira EA, Rasslan S. Surgical education in Brazil. World J Surg. 2010;34(5):880-3.

3. Gutiérrez VP. Surgical education in Argentina. World J Surg. 2010;34(5):877-9.

4. Nácul M. Aspectos atuais do ensino da videocirurgia no Brasil Uma análise crítica [editorial]. Rev Bras Videocir. 2004;2(1):1-4.
5. Shen BY, Zhan Q. Surgical education in China. World J Surg. 2008:32(10):2145-9.

6. Udwadia TE, Sen G. Surgical training in India. World J Surg. 2008;32(10):2150-5

7. Rogers DA, Elstein AS, Bordage G. Improving continuing medical education for surgical techniques: applying the lessons learned in the first decade of minimal access surgery. Ann Surg. 2001;233(2):159-66.

8. Gadacz TR, Talamini MA. Traditional versus laparoscopic cholecystectomy. Am J Surg. 1991;161(3):336-8. 
9. Zucker KA. Training issues [editorial]. Surg Laparosc Endosc 1992;2:187.

10. Rock JA, Warshaw JR. The history and future of operative laparoscopy. Am J Obstet Gynecol. 1994;170(1 Pt 1):7-11.

11. Gates EA. New surgical procedures: can our patients benefit while we learn? Am J Obstet Gynecol. 1997;176(6):1293-8; discussion 1298-9.

12. Reznick R. Let's not forget that CME has an "E". Foc Surg Ed. 1999;17:1-2

13. Gröne J, Ritz JP, Buhr HJ, Lauscher JC. Sustainability of skill courses for general and visceral surgery-evaluation of the long-term effect. Langenbecks Arch Surg. 2010;395(3):277-83.

14. Starr RA, Wagstaff NV. Implementing a surgical skills training program. Obstet Gynecol Clin North Am. 2006;33(2):247-58, viii.

15. Patil NG, Cheng SW, Wong J. Surgical competence. World J Surg. 2003;27(8):943-7.
16. Cuschieri A, Francis N, Crosby J, Hanna GB. What do master surgeons think of surgical competence and revalidation? Am J Surg. 2001;182(2):110-6.

17. Satava RM, Gallagher AG, Pellegrini CA. Surgical competence and surgical proficiency: definitions, taxonomy, and metrics. J Am Coll Surg. 2003;196(6):933-7.

Received on 15/04/2014

Accepted for publication 20/05/2014

Conflict of interest: none.

Source of funding: none.

Address for correspondence:

Marcelo de Paula Loureiro

E-mail:mpailoureiro@gmail.com 